\title{
The role of endoscopic dilation and stents in refractory benign esophageal strictures: a retrospective analysis
}

Qing Lư ${ }^{1 \dagger}$, Hailin Yan ${ }^{1 \dagger}$, Yilan Wang ${ }^{1}$, Tiantian Lei ${ }^{2}$, Linlin Zhu' ${ }^{1}$, Hongsheng Ma ${ }^{2^{*}}$ and Jinlin Yang ${ }^{1 *}$

\begin{abstract}
Background: The outcomes of patients with refractory benign esophageal strictures (RBES) are unclear, and the clinical efficacy of dilation versus stent placement is lacking. Our objective was to explore the role of endoscopic dilation and stents placement in the management of RBES.
\end{abstract}

Methods: RBES patients treated with dilation and stents in our hospital between January 2009 and December 2017 were included in this study. The primary outcomes were to assess clinical effectiveness and adverse events. The secondary outcome was to identify factors that predicted the dysphagia-free period.

Results: Among 75 RBES patients (54 male; median age 59 years), 39 (52\%), 20 (26.7\%), 3 (4\%), 10 (13.3\%), and 3 (4\%), were postsurgical, post-ESD, achalasia of cardia, caustic and mixed etiology, respectively. The median number of endoscopic therapy was 5 times (range 3, 21). Endoscopic therapy was successful in 46 patients (61.3\%). Patients treated with dilation showed a higher success rate $(70.9 \%, 39 / 55)$ than that treated with stents $(35 \%, 7 / 20)$. Fifteen patients died during follow-up. Nineteen patients had adverse events after endoscopic therapy. In total, the mean dysphagia-free period was 3.4 months $(95 \% \mathrm{Cl}, 2.5-4.3)$. The patients treated with dilation demonstrated a dysphagia-free period of 3.7 months $(95 \% \mathrm{Cl}, 2.7-5)$, while patients treated with stents displayed a dysphagia-free period of 2.3 months $(95 \% \mathrm{Cl}, 1.5-3)$. The dysphagia-free period had a linear growth trend over time, with an increase of 12 days per endoscopic therapy.

Conclusion: The dysphagia-free period increased by 12 days per endoscopic therapy, so the endoscopic therapy tended to be effective in patients with RBES by increasing the dysphagia-free period. However, compared to dilation therapy, stent therapy was not effective in increasing the dysphasia-free period and reducing the times and frequency of dilation. In addition, univariate and multivariate analyses also indicated that etiology may predict the endoscopic therapy outcome.

Trial registration: This study was retrospectively registered and approved by the Ethics Committee of West China Hospital of Sichuan University (IRB number: ChiCTR1800016321).

Keywords: Refractory benign esophageal strictures, Esophageal dilation, Esophageal stents, Long-term outcomes, Retrospective analysis

\footnotetext{
*Correspondence: mahongsheng63@163.com; mouse-577@163.com

Qing Lu and Hailin Yan Share first authorship.

${ }^{2}$ Department of Day Surgery, West China hospital of Sichuan University, 37

Guoxue Road, Chengdu 610041, Sichuan, China

'Department of Gastroenterology, West China Hospital of Sichuan University,

No.37 Guo Xue Alley, Chengdu 610041, Sichuan Province, China
}

(c) The Author(s). 2019 Open Access This article is distributed under the terms of the Creative Commons Attribution 4.0 International License (http://creativecommons.org/licenses/by/4.0/), which permits unrestricted use, distribution, and reproduction in any medium, provided you give appropriate credit to the original author(s) and the source, provide a link to the Creative Commons license, and indicate if changes were made. The Creative Commons Public Domain Dedication waiver (http://creativecommons.org/publicdomain/zero/1.0/) applies to the data made available in this article, unless otherwise stated. 


\section{Background}

Benign strictures of the esophagus are presumed to be a sequela of deep esophageal injury, which stimulates production of fibrous tissue and deposition of collagen, in the absence of endoscopic or pathological evidence of malignant strictures. Benign strictures of the esophagus include peptic esophageal strictures caused by long-term acid reflux (reflux esophagitis), caustic esophageal strictures, postsurgical esophageal strictures, post-endoscopic submucosal dissection (ESD) esophageal strictures, strictures caused by local radiotherapy, or tuberculosis $[1,2]$. The management of patients with benign esophageal stricture is time-consuming and challenging. Dilation with bougies or balloons is the classic treatment for esophageal strictures [3], but over $30 \%$ of patients need continuing endoscopic dilation for more than 2 sessions during longterm follow-up [4, 5]. Kochman defined RBES as more than 3-5 dilations having been performed without clinical and endoscopic response or when it was impossible to achieve a $14 \mathrm{~mm}$ lumen over 3 dilation sessions $[6,7]$. Some studies suggest temporary placement of selfexpandable stents for RBES when dilation has failed, though a clear definition of clinical failure has not been uniformly adopted. Stents were left to remodel the scar tissue. RBES patients with stents could alleviate symptoms of dysphagia and reduce the frequency of dilation [8,9]. Current research confirms that both dilation and stents for RBES are effective, but literature is scarce on the clinical efficacy of dilation versus stents. In addition, the long-term outcomes of RBES remain unclear. In our study, patients were followed for 6 months to assess the long-term outcomes, safety, and efficacy of endoscopic therapy in patients with RBES after at least 3 endoscopic therapy sessions.

\section{METHODS}

\section{Patients}

This is a single-center retrospective study. One thousand forty-six patients with esophageal strictures were treated by dilation or stents between January 2009 and December 2017 in our hospital, and we excluded the patients with endoscopic incision. All medical records were retrospectively reviewed. Patients were included in the study if (1) they had been diagnosed with esophageal benign stricture according to clinical manifestation, gastroscopy, and pathology, (2) they had persistent symptoms of dysphagia with at least three sessions of endoscopic therapy, and (3) they had complete medical records and follow-up information, including gender, age at first therapy, RBES etiology, number, location, length and diameter of strictures, endoscopic therapy, the period between two consecutive endoscopic interventions, and adverse events. Patients were excluded if they (1) were younger than 16 years old, (2) had received less than 3 endoscopic interventions, (3) had been diagnosed with congenital esophageal stenosis, malignant esophageal strictures, or with esophageal fistula (Fig. 1). This study was approved by the Ethics Committee of West China Hospital of Sichuan University (IRB number: ChiCTR1800016321).

\section{Equipment and procedure}

Patients were treated following local clinical practice in accordance with best practices. Gastroscopes (JIF Q260 or JIF - Q260J, Olympus Medical Systems, Tokyo, Japan) were used according to the stricture characteristics and type of treatment. Each physician had over 10 years' experience in endoscopy. Written consent for endoscopic dilation and stent was obtained before the operations. All patients received the standard dilation, by balloons and bougies or fully covered self-expandable metal stents (SEMSs) (MTN-SE C-membrane; 60-140 m; $20 \mathrm{~mm}$; MicroTech, Nanjing, China). The dilation procedures were performed with a through-the-scope balloon (Type 5842; 3 ATM-12 mm, 4.5 ATM-13.5 mm, 8 ATM-15 mm; Boston Scientific Corp; Marlborough, America) and savary bougies system (Savary-Gilliard Dilator set, type SGD-70-1; length: $70 \mathrm{~cm}$, diameters: 5 $\mathrm{mm}, 7 \mathrm{~mm}, 9 \mathrm{~mm}, 11 \mathrm{~mm}, 12.8 \mathrm{~mm}, 14 \mathrm{~mm}, 15 \mathrm{~mm}$; Wilson-Cook Medical, America). Dilation was the standard treatment for all patients, with other alternatives, such as stents placed on a case-by-case basis at the discretion of the endoscopist performing the procedure, after an appropriate discussion with surgeons and a dietician, as needed. Patients with RBES undergoing esophageal dilation required multiple sessions, every 2 to 4 weeks or longer. Some patients with persistent dysphagia symptoms were unable to achieve acceptable symptom relief and needed an intensive dilation schedule, (e.g. as frequent as every 2 to 3 days). However, in our study, we considered all subsequent endoscopic interventions within 7 days as one treatment cycle. In our study stent removal was after performed 6-8 weeks (range 4-10 weeks) later to allow scar tissue remodeling.

\section{Endpoints}

The primary outcomes were to assess clinical effectiveness and adverse events. Endoscopic therapy success was defined as a persistent dysphagia-free period, with no need for any other interventions, lasting at least 6 months [10]. Treatment failure was defined as the need for any endoscopic intervention, including surgery [11], during the follow-up period. Adverse events included esophageal fistula, bleeding, stent dysfunction (stent overgrowth, stent migration and food impaction), endoscopy to readjust or remove stents, and intolerable chest pain. Early and late adverse events were defined as those occurring within 7 days and later than 7 days after 


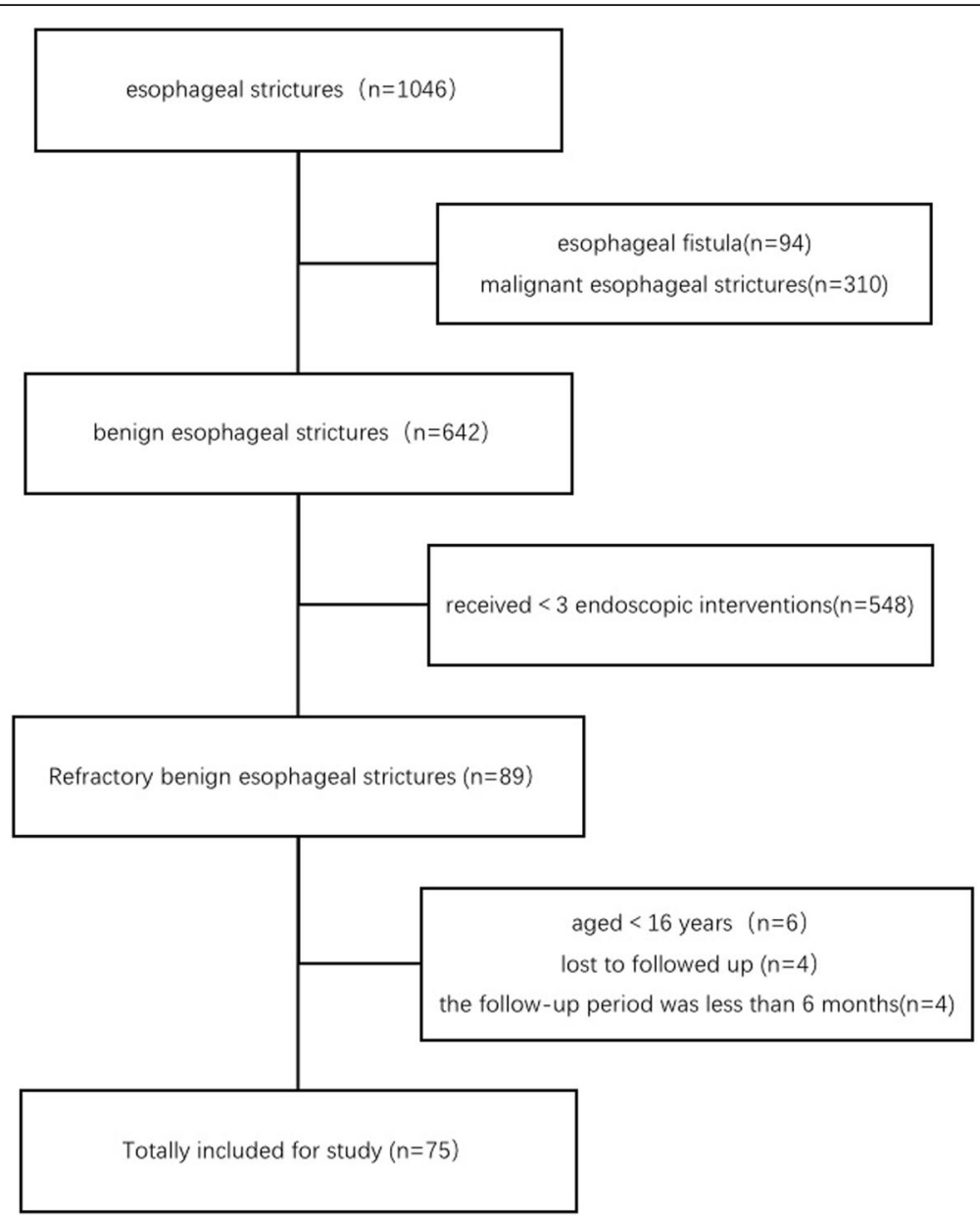

Fig. 1 Flowchart of patients with RBES

stenting, respectively. The secondary outcome was to identify factors that affected the dysphagia-free period. A dysphagia-free period was defined as a time interval between two subsequent endoscopic interventions greater than 7 days. We considered all endoscopic interventions within 7 days as only one treatment cycle. All patients were followed via telephone contact from the third therapy session until study termination or patient death to assess symptom resolution.

\section{Statistical methods}

Descriptive statistics were reported as median or mean and range for continuous variables. The chi-square test and the Fisher's exact test were used for categorical variables, and the $t$ test was used for continuous variables. We used logistic regression analysis to estimate the risk factors influencing treatment success. To explore the trend in dysphagia-free period length over time, we used hierarchical linear models. The medical data of patients with RBES were divided into two layers. The dilation times were the first layer of data (dysphagia-free period), and the characteristics of the patient, stricture and therapy were the second layer (gender, age, etiology, number, location and length of strictures, initial dysphagia-free period, and endoscopic therapy). The hierarchical linear models explored prognostic factors that were associated independently with a trend in the dysphagia-free period. All nonnormal data were transformed to normality. The dysphagia-free period analyses were performed using HLM Statistics version 6 (Scientific Software International Inc., Lincolnwood, IL), and all other statistical analyses were performed using SPSS Statistics version 22.0 (IBM Corp, Armonk, NY). $P$ values $<0.05$ were considered to indicate statistical significance.

\section{Results}

\section{Subject baseline characteristics}

Patient characteristics are shown in Table 1. In total, 75 RBES patients were included (54 male; median age, 59 years) (Fig. 1). Among these 75 patients, 39 (52\%), 20 (26.7\%), 10(13.3\%), 3 (4\%), 3 (4\%) showed esophageal strictures due to surgery, ESD, caustic injury, mixed 
Table 1 The characteristics of 75 patients with RBES and univariate analysis of endoscopic treatment success

\begin{tabular}{|c|c|c|c|}
\hline Category & & $\begin{array}{l}\mathrm{N}(\%) / \mathrm{M} \\
\text { (range) }\end{array}$ & $P^{c}$ \\
\hline \multirow[t]{2}{*}{ Sex } & Female & $21(28)$ & 0.554 \\
\hline & Male & $54(72)$ & \\
\hline Age (year) & - & $59(16,75)$ & 0.94 \\
\hline \multirow[t]{5}{*}{ Etiology ${ }^{a}$} & ESD/ESTD & $20(26.7)$ & 0.040 \\
\hline & Surgery & $39(52)$ & \\
\hline & $\begin{array}{l}\text { Achalasia of } \\
\text { cardia }\end{array}$ & $3(4)$ & \\
\hline & Caustic & $10(13.3)$ & \\
\hline & Mixed & $3(4)$ & \\
\hline \multirow[t]{4}{*}{ Location of strictures $^{a}$} & Cervical & $9(12)$ & 0.872 \\
\hline & Thoracic & $59(78.7)$ & \\
\hline & Ventral & $4(5.3)$ & \\
\hline & Mixed $^{b}$ & $3(4)$ & \\
\hline \multirow[t]{3}{*}{ Number of strictures } & One & $56(74.7)$ & 0.201 \\
\hline & Two & $14(18.7)$ & \\
\hline & Three or more & $5(6.6)$ & \\
\hline Length of strictures (cm) & - & $2(0.5,10)$ & 0.923 \\
\hline Diameter of strictures (mm) & - & $4(1,8.5)$ & 0.240 \\
\hline $\begin{array}{l}\text { Diameter of strictures after } \\
\text { dilation }(\mathrm{mm})\end{array}$ & - & $10(5,15)$ & 0.756 \\
\hline Times & - & $5(3,21)$ & $\begin{array}{l}< \\
0.001\end{array}$ \\
\hline Dysphagia-free period & - & $71(15,777)$ & 0.585 \\
\hline \multirow[t]{2}{*}{ Endoscopic therapy } & $\begin{array}{l}\text { Stents + } \\
\text { Dilation }\end{array}$ & $20(26.7)$ & 0.005 \\
\hline & Dilation only & $55(73.3)$ & \\
\hline
\end{tabular}

RBES Refractory benign esophageal strictures

${ }^{a}$ : Fisher's exact test

${ }^{b}$ : The mixed etiology was the patient with RBES caused by caustic injury and esophageal anastomosis following colon surgery

c: $P$ indicates a significant relationship between characteristics of patients and endoscopic therapy in univariate analysis

etiology, and achalasia of cardia, respectively. Achalasia of cardia was considered as benign stenosis according to the UK guidelines on oesophageal dilation [12]. The mixed etiology patients causing by caustic injury firstly, after esophageal anastomosis colon surgery, had persistent dysphasia after receiving several dilation sessions. Among the 75 cases, 9 (12\%), 59 (78.7\%), 4 (5.3\%), 3 (4\%) demonstrated esophageal strictures in the cervical esophagus, thoracic esophagus, ventral esophagus, and both cervical and thoracic esophagus, respectively. 56 (74.7\%) patients had a single stricture, 14 (18.7\%) had two strictures, and 5(6.6\%) patients had three or more strictures. The median strictures length was $2 \mathrm{~cm}(0.5$ $\mathrm{cm}, 10.0 \mathrm{~cm}$ ), the median strictures diameter was $4 \mathrm{~mm}$ $(1.0 \mathrm{~mm}, 8.5 \mathrm{~mm})$, and the median strictures final diameter reached after each dilation session was $10 \mathrm{~mm}(5$ $\mathrm{mm}, 15 \mathrm{~mm}$ ). All 75 patients received repeated endoscopic dilations. The median number of endoscopic therapies was 5 (range 3,21), and a mean of 1.9 (range 1, 6) SEMSs were placed in $20(26.7 \%)$ patients. The mean time of stent placement was 29 days (range 7,67 ). The median follow-up time was 31 months (range 6, 106).

\section{Dysphagia-free period}

Overall, the mean dysphagia-free period of all 75 patients was 3.4 months (95\% CI, 2.5-4.3). The dysphagiafree periods in patients treated with dilation and stents were 3.7 months (95\% CI, 2.7-5), and 2.3 months (95\% CI, 1.5-3), respectively. To explore the trend in the dysphagia-free period over time, we used hierarchical linear models (Table 2). The result of the fixed effect intercept and slope was significant $(P<0.001)$. The dysphagia-free period had a linear growth trend over time, with an increase of 12 days per endoscopic therapy (95\% CI, 8.7-16.7). The last dysphagia-free period was estimated to be 72 days (95\% CI, 61.8-83.6). We included patient characteristics, therapy characteristics and stricture characteristics in the second level data to estimate prognostic factors associated independently with the trend in the dysphagia-free period. There was no significant correlation between the dysphagia-free period time trend and patient age, sex, etiology, stricture location, stricture number, stricture length, therapy, or initial dysphagia-free period. However, achalasia of cardia $(p<0.001,95 \% \mathrm{CI}, 97.5-210.9)$, postsurgical strictures $(p=0.046,95 \% \mathrm{CI},-4.4-47.2)$, stricture length more than $2 \mathrm{~cm}(p=0.015,95 \% \mathrm{CI},-48--5.6)$ and initial dysphagia-free period ( $<<0.001,95 \% \mathrm{CI}, 36.3-68.3$ ) tended to positively correlated with the intercept of the dysphagia-free period time-trend. The achalasia of cardia patients and postsurgical strictures with the stricture length less than $2 \mathrm{~cm}$ had longer dysphagia-free periods, compared with those patients with post-ESD strictures and stricture length more than $2 \mathrm{~cm}$. Random-effects results showed that the variance component of the second data layer was large, due to the large variation among patients. The variance component, however, significantly decreased in the second level after excluding some stricture characteristics, especially stricture length, number and location. As such, compared with patients and therapy characteristics, stricture characteristics explain more of the variation in the time-trend of the dysphagia-free period.

\section{Clinical outcomes and adverse events}

Endoscopic therapy was successful in 46 (61.3\%) patients. The success rate of dilation treatment $(70.9 \%$, $39 / 55)$ was higher than that of stents $(35 \%, 7 / 20)$. Endoscopic treatment failed in $29(38.7 \%)$ patients. In 27 (36\%) patients, the end of follow-up was coincident with 
Table 2 The time-trend of dysphagia-free period with RBES in the model of HLM

\begin{tabular}{l} 
Fixed effects \\
\hline Times \\
Patient characteristics \\
Female-reference category \\
Male \\
Age \\
Stricture characteristics \\
Etiology \\
ESD/ESTD-reference category \\
Achalasia of cardia \\
Surgery
\end{tabular}

Location

$$
\begin{aligned}
& \text { Intercept (d) } \\
& \text { Time-trend (d/time) } \\
& \text { Intercept (d) } \\
& \text { Time-trend (d/time) }
\end{aligned}
$$

$$
\begin{aligned}
& \text { Intercept (d) } \\
& \text { Time-trend (d/time) } \\
& \text { Intercept (d) } \\
& \text { Time-trend (d/time) }
\end{aligned}
$$

Intercept (d)

Time-trend (d/time)

Intercept (d)

Intercept (d)

Time-trend (d/time)

Intercept (d)

Time-trend ( $\mathrm{d} /$ time)

$$
\begin{aligned}
& \text { Intercept (d) } \\
& \text { Time-trend (d/time) } \\
& \text { Intercept (d) } \\
& \text { Time-trend (d/time) }
\end{aligned}
$$

Length

$$
\begin{aligned}
& <2 \mathrm{~cm} \text {-reference category } \\
& \geq 2 \mathrm{~cm}
\end{aligned}
$$

Number

One-reference category

Two or more

Therapy characteristics

Initial dysphagia-free period

Intercept (d)

Time-trend (d/time)

Intercept $(d)$
Time-trend (d/time)

\begin{tabular}{ll} 
Parameter $(95 \% \mathrm{Cl})$ & $\mathrm{P}$ \\
\hline $72.7(61.8-83.6)$ & $<0.001$ \\
$12.7(8.7-16.7)$ & $<0.001$
\end{tabular}

$12.7(8.7-16.7)$

$\begin{array}{ll}75.1(54.3-95.9) & <0.001 \\ 10.5(2.3-18.7) & 0.014 \\ -3.2(-27.8-21.4) & 0.802 \\ 6.1(-4.0-16.2) & 0.236\end{array}$

$83.3(46.4-120.2) \quad<0.001$

$23.6(8.6-38.6)<0.001$

$-0.17(-0.8-0.4) \quad 0.557$

$-0.17(-0.4-0.1) \quad 0.193$

$57.6(35.6-79.6)<0.001$

$14.7(8.6-20.8) \quad 0.001$

$154.2(97.5-210.9) \quad<0.001$

$-0.54(-21.9-20.8) \quad 0.971$

$21.4(-4.4-47.2) \quad 0.046$

$9.01(-6.7-24.7) \quad 0.154$

$-1.19(-21.0-18.6) \quad 0.931$

$-4.50(-16.6-7.6) \quad 0.575$

$32.8(7.1-58.5) \quad 0.015$

$5.53(-4.3-15.3) \quad 0.273$

$1.75(0.7-2.8) \quad 0.002$

$0.36(-0.1-0.8) \quad 0.101$

$87.7(71.7-103.7) \quad<0.001$

$17.6(9.4-25.8) \quad<0.001$

$-26.8(-48--5.6) \quad 0.015$

$-6.32(-16.1-3.5) \quad 0.212$

$79.9(67.2-92.6)<0.001$

$14.9(9.8-20.0)<0.001$

$-24.8(-48--1.6) \quad 0.040$

$-6.57(-14.8-1.7) \quad 0.123$

$\begin{array}{lll}\text { Intercept (d) } & 52.3(36.3-68.3) & <0.001 \\ \text { Time-trend (d/time) } & 17.6(10.0-25.2) & <0.001 \\ \text { Intercept (d) } & 0.46(0.2-0.7) & 0.010 \\ \text { Time-trend (d/time) } & -0.12(-0.3-0.1) & 0.229\end{array}$


Table 2 The time-trend of dysphagia-free period with RBES in the model of HLM (Continued)

\begin{tabular}{llll}
\hline Fixed effects & & Parameter $(95 \% \mathrm{Cl})$ & \\
\hline Therapy & & & \\
Dilation + Stents-reference category & Intercept (d) & $74.9(61.5-88.3)$ & $<0.001$ \\
& Time-trend (d/time) & $17.4(11.1-23.7)$ & $<0.001$ \\
Stents & Intercept (d) & $-6.6(-30.1-16.9)$ & 0.583 \\
& Time-trend (d/time) & $-7.6(-16.6-1.4)$ & 0.103 \\
\hline
\end{tabular}

RBES Refractory benign esophageal strictures

$\mathrm{Cl}$ Confidence interval

HLM Hierarchical linear Model

the last endoscopic treatment. One (1.4\%) patient was treated with surgery, and another (1.4\%) patient was treated with endoscopic gastrostomy feeding tubes. Nineteen patients had adverse events after endoscopic therapy. Six (8\%) patients experienced esophageal fistula, caused by ESD (1/75), surgery (1/75), caustic (2/75) and mixed etiology (2/75), respectively. Three (4\%) patients experienced intolerable chest pain, and one (1.3\%) patient experienced bleeding. Ten (13.3\%) patients experienced stent dysfunction including stent overgrowth in 3 (4\%), stent migration in $6(8 \%)$ and food impaction in 5 (6.7\%) (Table 3). Fifteen patients died during follow-up, including lung and stomach tumor metastasis, severe pulmonary infection, and other causes unrelated to any endoscopic procedure.

There was a significant correlation between endoscopic treatment success and etiology, number of dilations and endoscopic therapy at univariate analysis (Table 1). In 39 patients with postsurgical stenosis, 18 patients had postoperative chemotherapy or radiotherapy. All the patients with a history of postoperative chemoradiation in our study had negative biopsies of the stricture. There was an insignificant correlation between therapy success and postoperative chemotherapy (95\% CI, $0.109-1.814 ; p=0.254)$ and postoperative radiotherapy (95\% CI, 0.131-1.907; $p=0.307)$. Comparing bougies with balloons dilation, it showed no difference in terms of clinical resolution $(p=0.137)$. There was an insignificant correlation between the diameter after each

Table 3 Adverse events of RBES

\begin{tabular}{lll}
\hline & Early period no. (\%) & Late periody no. (\%) \\
& $N=5$ & N=14 \\
\hline Stent overgrowth & 0 & 3 \\
Stent migration & 0 & 6 \\
Food impaction & 0 & 5 \\
Fistula & 1 & 5 \\
Bleeding & 1 & 0 \\
Intolerable chest pain & 3 & 0 \\
\hline
\end{tabular}

RBES Refractory benign esophageal strictures

Early and late adverse events: were defined as those occurring within 7 days and later than 7 days after stenting dilatation session $(p=0.756)$ and the length of stenosis $(p=0.923)$ with endoscopic treatment success at univariate analysis. We included sex, age, etiology, dilation times, and location of strictures in the multivariate analysis. The multivariate analysis (Table 4) revealed that postsurgical strictures (OR, 13.082; 95\% CI, 1.708$100.173 ; P=0.013$ ) and therapy times (OR, $1.714 ; 95 \%$ CI, $1.267-2.319 ; P<0.001)$ were the significant predictive factors for clinical resolution. The probability of endoscopic treatment failure was high in patients with postsurgical strictures. Both univariate and multivariate analyses suggested a correlation between etiology and clinical outcome. Therefore, we divided the etiology into four subgroups. The wide confidence interval of postsurgical strictures maybe caused by too many subgroups. It still had certain clinical significance. We conclude that the number of dilation was directly correlated with the probability of endoscopic treatment failure. Meanwhile, age (OR, 0.931; 95\% CI, 0.868-0.998; $P=0.043$ ) and

Table 4 Multivariate analysis of RBS

\begin{tabular}{|c|c|c|c|}
\hline & Success no. (\%) & $P$ & OR (95\% Cl) \\
\hline & \multicolumn{3}{|l|}{$N=46$} \\
\hline \multicolumn{4}{|l|}{ Sex } \\
\hline Male & $32(59.2 \%)$ & 0.581 & $1.298(0.514-3.276)$ \\
\hline Female & $14(66.7 \%)$ & 0.581 & $0.77(0.305-1.944)$ \\
\hline Age & - & 0.043 & $0.931(0.868-0.998)$ \\
\hline \multicolumn{4}{|l|}{ Etiology } \\
\hline Achalasia of cardia & $2(66.6 \%)$ & 0.878 & $0.749(0.019-30.15)$ \\
\hline ESD/ESTD & $10(50 \%)$ & 0.106 & $5.072(0.707-36.363)$ \\
\hline Surgery & $22(56.4 \%)$ & 0.013 & $13.082(1.708-100.173)$ \\
\hline Caustic $^{a}$ & $12(92.3 \%)$ & 0.012 & $0.02(0.001-0.418)$ \\
\hline Times & - & $<0.001$ & $1.714(1.267-2.319)$ \\
\hline \multicolumn{4}{|l|}{ Location of strictures $^{b}$} \\
\hline Upper $(\leq 20)$ & $12(54.5 \%)$ & 0.351 & $1.748(0.540-5.659)$ \\
\hline Middle $(20<n \leq 30)$ & $25(62.5 \%)$ & 0.891 & $1.069(0.413-2.764)$ \\
\hline Distal (>30) & $9(69.2 \%)$ & 0.392 & $0.535(0.128-2.243)$ \\
\hline
\end{tabular}

RBES Refractory benign esophageal strictures

${ }^{a}$ : Caustic and Mixed

b: By endoscopy: Upper esophagus defined as $\leq 20 \mathrm{~cm}$ from the incisors, Middle esophagus $20 \mathrm{~cm}$ to $30 \mathrm{~cm}$ from the incisors, Distal esophagus $>30$ from the incisors 
caustic strictures (OR, 0.02; 95\% CI, 0.001-0.418; $P=$ $0.012)$ were related to clinical resolution. The treatment outcome tended to be better with age. But the statistical significance was weak. It hardly to say that there was clear clinical significance. Sex and other stricture characteristics were not significant predictive factors.

\section{Discussion}

There is no universal definition for RBES, and the exact number of additional dilation sessions required before categorizing strictures as refractory varies among different series. In this study, we defined RBES as refractory to at least 3 endoscopic treatment sessions. One thousand forty-six patients with esophageal strictures were treated by dilation or stents between January 2009 and December 2017 in our hospital. Less than 10\% population was the non-local population from other province, and the majority was the local population of Sichuan province. Almost all the Chinese people belong to the yellow race and same ethnic group. So the patients are very representative, and are considered as a homogeneous population. We established the database and selected patients with a medical record of nearly 8 years. Three-fifths of the patients achieved endoscopic therapy success, and nearly two-fifths of patients required constant endoscopic treatment before the end of the follow-up.

In our study, increased number of dilation was associated with a greater probability of endoscopic treatment failure. We considered that each round of dilation may entail multiple dilations, and patients with RBES may have negative results in long-term follow-up.

We also found that endoscopic therapy tended to increase the dysphagia-free period per dilation in patients with RBES. In most prior esophageal strictures researches, dysphagia score was often used as the endpoint without a consistent standard. However, in our study, the mean length of the dysphagia-free period was considered a proxy for survival quality. Our study showed the dysphagia-free period had a linear growth time trend, with an increase of 12 days per endoscopic therapy. We found no significant predictive factors for this growth rate.

The clinical outcomes of RBES relied on stricture features. The dysphagia-free period was more varied by features of stenosis as compared to the characteristics of patients and therapy. In addition, different stricture etiologies, with different mechanisms, may have different outcomes. Univariate and multivariate analyses explained that etiology may predict the endoscopic therapy outcomes. Postsurgical stricture etiology was a significant predictive factor for treatment failure in this study. The pathogenesis of anastomotic structures was due to reflux of corrosive gastric contents, ischemia of the residual tissue and inconsistencies of local hyperplasia $[13,14]$. For post-ESD strictures, the residual ulcer surface may undergo self-repair, leading to fibrous overgrowth and scar contracture [15]. Therefore, we hypothesize that temporary endoscopic treatment was ineffective to change the depth of the esophageal wall and fiber formation. Caustic strictures were associated with a greater need for subsequent dilatations, due to that a long-lasting local inflammatory process leads to tissue fibrosis, transmural process and irreversible deposition of collagen [16]. In the multivariate analysis, caustic strictures were related to clinical resolution. However, we hypothesize caustic strictures tend to not have total clinical resolution after repeated endoscopy therapy, because of the longer dysphagia-free period ( $>6$ months) and subsequent late interventions. Among the caustic stricture patients, three patients underwent surgical intervention. For radiationinduced strictures, a high long-term recurrence rate of up to $33 \%$ has been shown, and $43 \%$ of these strictures were refractory to dilation therapy [17]. Post-radiotherapy strictures have been reported to account for $12 \%$ of benign strictures [18]. In our study, we did not separate postoperative chemoradiotherapy from postsurgical stenosis, but we found no statistical correlation between postsurgical chemoradiotherapy and clinical resolution.

It is difficult to say whether SMESs provide dysphagia relief in patients with RBES. Stents were left to remodel scar tissue, prevent stricture recurrence and improve dysphagia. Accordingly, some RBES patients experienced alleviation of dysphagia symptoms and reduced dilation times by stents [19]. However, this study showed that compared to dilation only, the dysphasia-free period of dilation with stents was not increased significantly. The result was same as the study of Repici. Repici concluded that once a stricture fits the definition of RBES, its prognosis relies on its being refractory, and endoscopic stenting does not affect the long-term natural history of the disease [20]. Stent therapy did not reduce the length and frequency of dilation.

On the other hand, the stents had more adverse events than dilation. A meta-analysis of eighteen studies (444 patients with RBES) conducted by Fuccio L et al. showed migration and adverse events rates of 28.6 and $20.6 \%$, respectively $[10,21]$. In our study, $31.6 \%$ patients $(6 / 19)$ had migration, and $47.4 \%$ patients $(9 / 19)$ had stentrelated adverse events. Esophageal fistula is also a major adverse event, occurring in 0.1 to $0.3 \%$ patients after dilation [22]. In our study, $8 \%(6 / 75)$ of patients had an esophageal fistula, and the incidence was higher in caustic strictures patients (4/6). Caustic esophageal stenosis, with deep and wide esophageal lesions involving the whole esophageal wall, had a greater association with surgery, compared to repeated dilations, which may have low security and high risk of esophageal fistula [23]. The 
mean length of stenting was 29 days. It means the most patients had enough duration of stenting. Only 7 sessions of stenting were removed less than 29 days. The short duration of stenting was caused by the complication and poor physical condition, such as stent migration and intolerable chest pain needing removing. In our study, the stents had more adverse events than dilation. The short-term adverse event leading to worse outcome was another evidence, which confirmed that the SMESs could not provide dysphagia relief than dilation.

Surgery was performed in $1.3 \%(1 / 75)$ of patients, indicating that endoscopic dilation was considered as an optimal and long-term option for the management of patients with RBES. The majority of patients with RBES still required repeated dilation sessions.

This study has 3 limitations. First, our study had a nonrandomized design and potential selection bias, which inherently decreases the statistical power of the results. Second, our study was a retrospective singlecenter design with small sample size. Finally, we did not analyze the influence of different stent types on RBES patient outcomes. The recent randomized study from Walter concluded that biodegradable stent placement is associated with temporary reduction in number of repeat dilations and prolonged time to recurrent dysphagia compared with dilation [24]. In our study we did not analyze the different stent types, but current guidelines do not recommend a specific type of stents to be superior to any other. To better identify the factors that predict endoscopic therapy efficacy, adverse events, and dysphagia-free period, a large, prospective, randomized, and controlled study is needed.

\section{Conclusion}

Overall, the dysphagia-free period increased by 12 days per endoscopic therapy, so the endoscopic dilation and stents tended to be effective in patients with RBES by increasing the dysphagia-free period. However, compared to dilation therapy, stent therapy was not effective in increasing the dysphasia-free period and reducing the times and frequency of dilation. The etiology of strictures may predict the endoscopic therapy outcome, and postsurgical strictures were a significant predictive factor for treatment failure.

\section{Abbreviations}

ESD: Endoscopic submucosal dissection; RBES: Refractory benign esophageal strictures; SEMSs: Self-expandable metal stents

\section{Acknowledgements}

Not applicable.

\section{Authors' contributions}

$\mathrm{QL}$ analyzed the data and wrote the paper. JY and HM designed the research. QL, HY, YW, TL, LZ performed the research. QL, HY, YW and TL performed the follow-ups. All authors read and approved the final manuscript.

\section{Funding}

This study was supported by the Science and Technology Department of Sichuan Province for Scientific Research in China (Nos.2014SZ0002-2 and 2015SZ0123). This funding funded our expenses for language modification of the article.

\section{Availability of data and materials}

The datasets analysed during the current study are not publicly available, but are available from the corresponding author on reasonable request.

\section{Ethics approval and consent to participate}

This study was retrospectively registered and approved by the Ethics Committee of West China Hospital of Sichuan University (IRB number: ChiCTR1800016321). Consent to participate was waived due to the fact that this is a retrospectively study with no risk to participants, where the research will not affect the rights or welfare of the participants.

\section{Consent for publication}

Not applicable.

\section{Competing interests}

Qing Lu, Hailin Yan, Yilan Wang, Tiantian Lei, Linlin Zhu, Hongsheng Ma, Jinlin Yang have no conpeting interest or financial ties to disclose.

Received: 12 July 2018 Accepted: 30 May 2019

Published online: 20 June 2019

\section{References}

1. Spechler SJ. American gastroenterological association medical position statement on treatment of patients with dysphagia caused by benign disorders of the distal esophagus. Gastroenterology. 1999;117:229-33.

2. Kobayashi S, Kanai N, Ohki T, Takagi R, Yamaguchi N, Isomoto H, et al. Prevention of esophageal strictures after endoscopic submucosal dissection. World J Gastroenterol. 2014;20(41):15098-109.

3. Standards of Practice Committee, Egan JV, Baron TH, Adler DG, Davila R, Faigel DO, et al. Esophageal dilation. Gastrointest Endosc. 2006;63(6):755-60.

4. Patterson DJ, Graham DY, Smith JL, Schwartz JT, Alpert E, Lanza FL, et al. Natural history of benign esophageal stricture treated by dilatation. Gastroenterology. 1983;85(2):346-50.

5. de Wijkerslooth LR, Vleggaar FP, Siersema PD. Endoscopic management of difficult or recurrent esophageal strictures. Am J Gastroenterol. 2011;106(12):2080-2091 quiz 2092.

6. Kochman ML, McClave SA, Boyce HW. The refractory and the recurrent esophageal stricture: a definition. Gastrointest Endosc. 2005;62(3):474-5.

7. Spaander MC, Baron TH, Siersema PD, Fuccio L, Schumacher B, Escorsell A, et al. Esophageal stenting for benign and malignant disease: European Society of Gastrointestinal Endoscopy (ESGE) clinical guideline. Endoscopy. 2016;48(10):939-48.

8. Repici A, Conio M, De Angelis C, Battaglia E, Musso A, Pellicano R, et al. Temporary placement of an expandable polyester silicone-covered stent for treatment of refractory benign esophageal strictures. Gastrointest Endosc. 2004;60(4):513-9.

9. Fiorini A, Fleischer D, Valero J, Israeli E, Wengrower D, Goldin E. Selfexpandable metal coil stents in the treatment of benign esophageal strictures refractory to conventional therapy: a case series. Gastrointest Endosc. 2000:52(2):259-62.

10. Fuccio L, Hassan C, Frazzoni L, Miglio R, Repici A. Clinical outcomes following stent placement in refractory benign esophageal stricture: a systematic review and meta-analysis. Endoscopy. 2016;48(2):141-8.

11. Young MM, Deschamps C, Trastek VF, Allen MS, Miller DL, Schleck CD, et al. Esophageal reconstruction for benign disease: early morbidity, mortality, and functional results. Ann Thorac Surg. 2000;70(5):1651-5.

12. Sami SS, Haboubi HN, Ang Y, Boger P, Bhandari P, de Caestecker J, et al. UK guidelines on oesophageal dilatation in clinical practice. Gut. 2018;67(6):1000-23.

13. Hirdes MM, van Hooft JE, Koornstra JJ, Timmer R, Leenders M, Weersma RK, et al. Endoscopic corticosteroid injections do not reduce dysphagia after endoscopic dilation therapy in patients with benign esophagogastric anastomotic strictures. Clin Gastroenterol Hepatol 2013;11(7):795-801.e791. 
14. Miyashita M, Onda M, Okawa K, Matsutani T, Yoshiyuki T, Sasajima K, et al. Endoscopic dexamethasone injection following balloon dilatation of anastomotic stricture after esophagogastrostomy. Am J Surg. 1997;174(4):442-4.

15. Isomoto H, Yamaguchi N, Minami H, Nakao K. Management of complications associated with endoscopic submucosal dissection endoscopic mucosal resection for esophageal cancer. Dig Endosc. 2013;25(Suppl 1):29-38.

16. Gumaste W, Dave PB. Ingestion of corrosive substances by adults. Am J Gastroenterol. 1992;87(1):1-5.

17. Agarwalla A, Small AJ, Mendelson AH, Scott FI, Kochman ML. Risk of recurrent or refractory strictures and outcome of endoscopic dilation for radiation-induced esophageal strictures. Surg Endosc. 2015;29(7):1903-12.

18. Piotet E, Escher A, Monnier P. Esophageal and pharyngeal strictures: report on 1,862 endoscopic dilatations using the Savary-Gilliard technique. Eur Arch Otorhinolaryngol. 2008;265(3):357-64.

19. Didden P, Spaander MC, Bruno MJ, Kuipers EJ. Esophageal stents in malignant and benign disorders. Curr Gastroenterol Rep. 2013;15(4):319.

20. Repici A, Small AJ, Mendelson A, Jovani M, Correale L, Hassan C, et al. Natural history and management of refractory benign esophageal strictures. Gastrointest Endosc. 2016;84(2):222-8.

21. Repici A, Hassan C, Sharma P, Conio M, Siersema P. Systematic review: the role of self-expanding plastic stents for benign oesophageal strictures. Aliment Pharmacol Ther. 2010;31(12):1268-75.

22. Hernandez LV, Jacobson JW, Harris MS. Comparison among the perforation rates of Maloney, balloon, and savary dilation of esophageal strictures. Gastrointest Endosc. 2000;51(4 Pt 1):460-2.

23. Da-Costa-Pinto EA, Dorsa TK, Altimani A, Andreollo NA, Cardoso SR, Morais DJ, et al. A functional study of caustic strictures of the esophagus in children. Braz J Med Biol Res. 2004;37(11):1623-30.

24. Walter D, van den Berg MW, Hirdes MM, Vleggaar FP, Repici A, Deprez PH, et al. Dilation or biodegradable stent placement for recurrent benign esophageal strictures: a randomized controlled trial. Endoscopy. 2018 Dec;50(12):1146-55.

\section{Publisher's Note}

Springer Nature remains neutral with regard to jurisdictional claims in published maps and institutional affiliations.

Ready to submit your research? Choose BMC and benefit from:

- fast, convenient online submission

- thorough peer review by experienced researchers in your field

- rapid publication on acceptance

- support for research data, including large and complex data types

- gold Open Access which fosters wider collaboration and increased citations

- maximum visibility for your research: over $100 \mathrm{M}$ website views per year

At $\mathrm{BMC}$, research is always in progress.

Learn more biomedcentral.com/submissions 